\title{
Extracorporeal Shockwave Lithotripsy: Initial Experience at Bahawalpur
}

\author{
RASOOL M. ${ }^{1}$, TABASSUM S.A. ${ }^{2}$, SHEIKH A.H. ${ }^{3}$, MUMTAZ F. ${ }^{4}$ \\ Address for Correspondence: Dr. Mumtaz Rasool, Senior Registrar, Urology, 81-A Shadab Colony, Baghdad Road, \\ Bahawalpur.
}

Place of Study: American Kidney Stone Centre (AKSC), Bahawalpur, a private setup.

Duration of Study: January 2005 to June 2007.

Design of Study: Prospective, Observational.

Material \& Methods: A total of 250 patients were evaluated for ESWL results. The one session comprised of 1500-2500 shocks with intermittent fluoroscopy with X-Ray focusing. A period of $7-10$ days was given between two sessions. The procedure was repeated till the clearance of stone no matter what was the number of sessions. The complications like pain, colic, hematuria were addressed adequately and immediately. The development of steinstrasse was initially observed and few required manipulation. The stone size is the only matter of concern in few patients especially lower pole stones.

Results: The stone clearance was achieved in 89\% of patients. Auxillary procedures were required in 10.8\% before ESWL and $9.6 \%$ of patients after ESWL. Which include Endoscopic stenting and manipulation with uretero-renoscopy and intracorporeal lithotripsy. Prophylactic insertion of DJ stenting reduced complication rate and incidence of steinstrasse.

Conclusion: ESWL can be safely recommended for patients of urolithiasis irrespective of age and stone size with promising results of stone clearance and patient acceptance.

Key Words: ESWL-Extracorporeal shock wave lithotripsy, URS-Ureterorenoscopy. ICL-Intracorporeal lithotripsy.

\section{Introduction}

Since the advent of Extracorporeal Shock Wave Lithotripsy in 1980s, the improvements in mechanics of lithotripters and better understanding of shock wave physics has made this mode of stone treatment, acceptable and more effective. The increasing availability of equipments and trained operating personnel has made ESWL an efficient mode of urinary stone treatment .The stone clearance achievement has also increased tremendously.

Many years after the first application, ESWL has gained world wide acceptance as first choice therapy for most of urolithiasis. Stones can be successfully fragmented by application of shock waves, but the ability of kidney and ureter to clear the resulting fragments is far more important in terms of successful treatment outcome. Increasing experience show some advantages, cost reduction, permanent monitoring, lack of exposure to ionizing radiation in ultrasound monitoring. ESWL is a safe procedure for the treatment of urolithiasis. Nevertheless follow-up of stone patients after ESWL is mandatory and ultimate goal for treating stones by whatever means is to get the patients stone free and prevent recurrence ${ }^{1}$. Over the last two decades there has been gradual increase in utilization of ESWL due to patient desire $^{2}$.

The urological approach to urolithiasis has changed with introduction of ESWL that allows relatively non invasive removal of stones. Nevertheless ESWL does not change the propensity of recurrence in stone and importance of medical prevention remains of paramount importance in the management of renal stone disease ${ }^{3}$.The optimal results of noninvasive procedures and advantages of ESWL for the patient like out patient and anesthesia free treatment and decreased morbidity has caused limited annual indications of open surgery for stone disease. Open surgery is now drastically reducing, endoscopic and extracorporeal methods are increasing ${ }^{4}$.

\section{Material and Methods}

The present study was conducted at private setup, American Kidney stone Centre, Bahawalpur as public sector do not possess ESWL facility. This is the first lithotripter in the town. The period of this study spans from January 2005 to June 2007.

The prospective observational study was conducted to determine efficacy, efficiency, patient tolerance, satisfaction, and acceptance to this mode of treatment for renal stones. The observation for outcome and number of sessions for total stone clearance were also noted along with total radiation dose given in one session and during whole treatment.

All patients who presented to us with renal stones were explained treatment options after all investigations. Those patients who opted for ESWL were included in this study. A total of 289 patients were included in this study. Four patients opted for open surgery after first session and thirty five patients did not turn up after first session of ESWL. These thirtynine patients were excluded and results were formulated in 250 patients.

Patients below five years of age, hypertensive patients, patients with uncontrolled diabetes, cardiac patients with 
pace makers, severe respiratory problem like bronchial asthma and patient whose intravenous urography showed pelviureteric junction obstruction were not included in this study.

About The Equipment Used:

Lithotripter in this private setup is of HM-3 type, hydroelectric with X-Ray focus using $\mathrm{C}$-arm fluoroscopy with vertical as well as side to side tiltable radiolucent table. The mechanics involved per session in this lithotripter are 3-5 MA, 90-98KV and 8-10 EKV. During one sitting 15002500 shocks are given with intermittent X-Ray focusing in order to reduce radiation exposure to the patient. Once fluoroscopy exposes the patient to $02 \mathrm{MA} / 50-60 \mathrm{KV}$ (Max upto $70 \mathrm{KV}$ of radiation).A gap of 7-10 days given during sessions. Single session to 12 sessions were required in patients to achieve complete clearance.

Few children required sedatives before lithotripsy. Investigations required were ultra sonography abdomen, serum urea, creatinine, X-Ray for KUB. Facilities for retrograde catheterization, endoscopic DJ stenting, Ureterorenoscopy with intra corporeal lithotripsy are also available in the same private setup.

\section{Results}

The total number of patients included in this study were 250 .Male to female ratio was 2.5to 1.

Age:

Age of the patients in this study was 5 years to 70 years (Table 1). Majority of patients 168/250 (67.2\%) were young adults between 21 to 50 years of age.

Table 1:

\begin{tabular}{|l|c|l|}
\hline Age & No. of Patients & \% age \\
\hline $05-20$ years & 51 & $20.4 \%$ \\
\hline $21-35$ & 113 & $45.2 \%$ \\
\hline $36-50$ & 55 & $22 \%$ \\
\hline $51-70$ & 31 & $12.8 \%$ \\
\hline
\end{tabular}

The number of sessions required depended upon size and site of stone. Staghorn calculi and major burden of stone in lower pole required more sessions. Maximum of 12 sessions were required in one patient with stone size of $56 \mathrm{~mm}$.

The total number of sessions in this setup was as follows; (Table 2).

Table 2:

\begin{tabular}{|l|c|c|}
\hline No of Sessions & No. of patient & \% age \\
\hline Single session & 61 & $24.4 \%$ \\
\hline $01-03$ sessions & 79 & $31.6 \%$ \\
\hline $04-06$ sessions & 99 & $39.6 \%$ \\
\hline $06-09$ sessions & 09 & $03.6 \%$ \\
\hline $09-12$ sessions & 02 & $0.8 \%$ \\
\hline
\end{tabular}

The single renal unit treatment strategy was exercised during ESWL in this setup, bilateral renal stones were treated as separate units. Simultaneous bilateral treatment with lithotripsy was not done in any patient. Patients with bilateral obstructive stone were treated with prophylactic bilateral endoscopic DJ stenting before embarking on ESWL in $10.8 \%$ of patients. The radiolucent stones were given intravenous contrast 05 minutes before ESWL in 43 (17.2\%) patients. In remaining 207 (82.8\%) patients, stones were radio opaque.

The requirements of auxiliary procedures in post ESWL patients were considered as failure of lithotripsy in $10.8 \%$ of patients. Auxiliary procedures, noted in our study were as follows; (Table 3).

Table 3:

\begin{tabular}{|c|l|c|}
\hline S. \# & \multicolumn{1}{|c|}{ Name of procedure } & No of Pts (\%) \\
\hline 1. & $\begin{array}{l}\text { Prophylactic DJ stenting } \\
\text { before ESWL }\end{array}$ & $27(10.8 \%)$ \\
\hline 2. & DJ stenting after ESWL & $14(5.6 \%)$ \\
\hline 3. & $\begin{array}{l}\text { Uretero-renoscopy and } \\
\text { Lithoclasty }\end{array}$ & $13(5.2 \%)$ \\
\hline
\end{tabular}

The size of stone ranged from $10 \mathrm{~mm}$ to $56 \mathrm{~mm}$ Results obtained in various sizes of stones were as follows (Table4).
Table 4:

\begin{tabular}{|c|l|c|c|c|}
\hline S. \# & \multicolumn{1}{|c|}{ Size of Stone } & $\begin{array}{c}\text { No of } \\
\text { Patients }\end{array}$ & $\begin{array}{c}\text { No of patients } \\
\text { cleared of stones }\end{array}$ & $\begin{array}{c}\% a g e \\
\text { clearance }\end{array}$ \\
\hline 1 & $10-15 \mathrm{~mm}$ & 69 & 69 & $100 \%$ \\
\hline 2 & $15-30 \mathrm{~mm}$ & 89 & 76 & $85.39 \%$ \\
\hline 3 & $30-45 \mathrm{~mm}$ & 77 & 67 & $87.01 \%$ \\
\hline 4 & $45-56 \mathrm{~mm}$ & 15 & 11 & $73.33 \%$ \\
\hline & Total No of patients & 250 & 223 & $89 \%$ \\
\hline
\end{tabular}

Out of 250 patients, 223 became free of stones, so overall clearance rate was $89 \%$.The patients were advised to maintain sufficient ambulatory lifestyle and increased amounts of oral liquids intake. The use of prophylactic antibiotics (usually ciprofloxacin) and analgesics (usually diclofenac sodium or potassium) were prescribed routinely to adult patients. 


\section{Complications}

Pain was the major complaint observed during this study. During session of lithotripsy 139 (55.6\%) patients had pain, who were managed by giving injectable diclofenac sodium intramuscularly during ESWL. Regular analgesics were advised to patients in between the session so as to facilitate painless passage of stone particles and gravel. Severe colic developed in 07 (2.8\%) patients requiring parentral analgesic. Fever developed in $32(12.8 \%)$ patients and high grade fever with rigors developed in 04 (1.6\%) patients requiring injectable antibiotics treatment and observation after admission with culture and sensitivity of urine. Nausea occurred in 76 (30.4\%) patients and vomiting in 03 (1.2\%) patients. One of these three patients needed admission for a day and settled.

The complication of steinstrasse developed in 21 (8.4\%) patients. These patients had stone size of $30 \mathrm{~mm}$ to $45 \mathrm{~mm}$. Steinstrasse developed in those patients who did not have auxiliary treatment with DJ stents before ESWL but required endoscopically manipulation afterwards and settled by clearance of all particle of stone gravel. Two of these patients required surgical intervention by open ureterolithotomy at lower end. While those patients who were stented before ESWL only 3 of them developed steinstrasse but gradually cleared of all gravel without requiring further intervention.

Hematuria observed in 36 (14.4\%) patients and this was transient and mild in majority and settled with increased intake of oral liquids while two of these thirty six patients needed admissions and injectable tranexamic acid along with IV fluids.

Retention of urine developed in $02(0.8 \%)$ patients because the stone particles in urinary bladder were larger than $09 \mathrm{~mm}$ and these two patients were having urethral stricture hindering the passage of these particles. These were managed by optical internal urethrotomy and litholapexy. Table 5.

Table 5:

\begin{tabular}{|c|l|c|c|}
\hline Sr \# & Complication & No. of pts & \% age \\
\hline 1. & Pain & 139 & $55.6 \%$ \\
\hline 2. & Colic & 07 & $02.8 \%$ \\
\hline 3. & Fever with Rigors & 32 & $12.8 \%$ \\
\hline 4. & Nausea \&Vomiting & 76 & $30.4 \%$ \\
\hline 5. & Haematuria & 36 & $14.4 \%$ \\
\hline 6. & Steinstrassee & 21 & $08.4 \%$ \\
\hline 7. & Retention of Urine & 02 & $0.8 \%$ \\
\hline
\end{tabular}

\section{Follow-up}

All patients who underwent ESWL were followed till the clearance of all stone particles. Minimum of 05 days and maximum of 120 days were required for spontaneous passage of stone particles depending upon stone size and location. The stones in upper ureter and renal pelvis cleared in less time as compared to lower pole stones. The follow up period ranged from 06 weeks to 60 weeks.

\section{Discussion}

The age of patients in this study ranged from 05years to 70 years with male to female ratio of 2.5:1.The age range in different studies about ESWL was 04yearsto 82 years ${ }^{5,6}$.The male to female ratio in different studies was $1: 1$ to $3: 1^{6,7}$. The total number of patients in our study was 250 which is sufficiently large number as compared to few dozen patients in different studies. ${ }^{1,5,6,8,9}$.

The size of stone in our study was $10 \mathrm{~mm}$ to $56 \mathrm{~mm}$.In literature majority of studies had stone size was less than 30 $\mathrm{mm}$ while in other studies stone size was larger upto 52 $\mathrm{mm} .{ }^{1,7,10-15}$ Stone size and number independently increase the probability of treatment failure ${ }^{8}$.Best results can be achieved by trained operator, high number of shocks and longer fluoroscopy time and narrow focal zone of $6.5 \mathrm{~mm}^{7}$. After ESWL residual fragments $4 \mathrm{~mm}$ or less are usually considered as clinically insignificant. ${ }^{16}$ The anatomy of the kidney collecting system may play a role in the selection of the best method of kidney stone treatment for a specific patient. For stones located in lower pole, the clearance rate after shockwave lithotripsy has been uniformly low relative to that for calculi elsewhere. ${ }^{17}$ Renal morphology was the only significant factor affecting stone free rate since stone clearance was significantly less in pyelonephritic kidneys. ${ }^{18}$ The frequency of residual stones can be reduced by appropriate indications of ESWL. Once a renal stone has formed, re-treatments with ESWL can not ensure complete elimination of the stones. ${ }^{19}$ ESWL was considered a failure if residual stone fragments remained after one month or an auxiliary procedure or retreatment was required. ${ }^{20}$ ESWL combined with urinary alkalinization in radiolucent uric acid stones achieves rapid resolution of large calculi. ${ }^{21}$ The total amount of ESWL emissions and hyperurecaemia independently affected probability of renal scar formation. Over emission of ESWL (more than 10,000 shocks) must be cared for prevention of renal scarring. After ESWL periodical checkup with ultrasonography will provide useful information. ${ }^{22}$ ESWL is highly effective for pediatric urolithiasis with minimal morbidity. Stone clearance is not adversely affected by stone size upto $30 \mathrm{~mm}$ however lower poler stones and impacted stones at PUJ have relatively poor clearance. $^{23}$ ESWL is simple effective and safe primary treatment in children with staghorn calculi. ${ }^{24}$

The complications observed during ESWL in this setup were mainly pain (55.6\%), nausea \& vomiting (30.4\%), Colic (02.8\%), Hematuria (14.4\%), Steinstrasse (8.4\%), Retention of urine $(0.8 \%)$. These complication rates were significantly higher than mentioned in literarture. Few patients required admissions and treatment, while in different studies similar complications along with development of pyonephrosis, petechial hemorrhages are mentioned. Pyo- 
nephrosis required nephrectomy ${ }^{25}$. Other studies mention similar complications as in our study and are at a rate of 8$11 \% .{ }^{6,23,26}$

Overall incidence of steinstrasse in literature was 3.97\% which significantly correlated with stone size, site, power level used and radiological features of stone. Steinstrasse was more common in renal stones of more than $2 \mathrm{~cm}$ size. If a patient has high probability of steinstrasse formation ,close follow-up with early intervention or prophylactic pre ESWL ureteral stenting is indicated ${ }^{3}$.In the study of AL-Awadi ${ }^{14}$, 400 patients with unilateral stone burden of $1.5-3.5 \mathrm{~cm}$ were assessed for development of steinstrasse after ESWL with stent and without stents. The development of steinstrasse was $6 \%$ in stented and $13 \%$ in non stented patients $(p<0.05)$. This particular study shows that the incidence of steinstrasse in lower third ureter depend on the size of calculus regardless of $\mathrm{J}$ stent presence being $2.6 \%$ for a stone of $1.5-2.0 \mathrm{~cm}$ and $56 \%$ for a stone of $3.1-3.5 \mathrm{~cm}(\mathrm{p}<0.001)$ and this resolved spontaneously in majority of both groups. The incidence of steistrasse increased with size of calculus. Presence of stent lowers the incidence of steinstrasse but has no significant effect on subsequent management of this complication of ESWL ${ }^{14}$. Steinstrasse in another study was managed with ureteroscopic manipulation ${ }^{27}$. In our study steinstasse was observed in 21 patients. This correlates with the fact that majority of our patients were with stone burden of 1.5 $\mathrm{cm}$ to $4.5 \mathrm{~cm}$. Out of these 21 patients, in 11 patients ureterorenoscopy and intracorporeal lithotripsy was done. In remaining 10 patients steinstrasse resolved spontaneously.

In case of bilateral renal calculi we planned staged fashion of ESWL at interval of 3-20 weeks instead of simultaneous treatment of both kidneys. Traditionally bilateral renal calculi have been managed by staged ESWL due to concern about bilateral obstruction ${ }^{10}$. In some studies bilateral synchronous ESWL was done and it was found to be safe and effective monotherapy for bilateral urolithiasis ${ }^{8}$. The effects of simultaneous versus staged ESWL on renal function as measured by serum creatinine were not statistically different. ${ }^{10}$ No patient developed bilateral obstruction or renal failure or deterioration of renal function ${ }^{8}$.

Monitoring during ESWL can be done with fluoroscopy or ultrasonography. Dose area product (DAP) measurements with USG $137 \mathrm{cGycm}^{2}$ equivalent to a mean effective dose of $0.24 \mathrm{mSv}$ while with fluoroscopy mean DAP of 552 $\mathrm{cGycm}^{2}$ with mean effective dose of $1.2 \mathrm{mSv}$.Ultrasound localization is better than fluoroscopic localization but where available pulsed fluoroscopy should be preferable ${ }^{28}$. In our study we have used pulsed fluoroscopic monitoring during the procedure so as to reduce exposure of ionizing radiation to patient. In one session the number of shocks given in our setup are between 1500 to 2500 with intermittent fluoroscopy for target localization thus reducing radiation exposure to 3-5MA, $50-60 \mathrm{Kv}$ and $8-10 \mathrm{EKv}$.The target is monitored 03-04 times per session. The number of shocks in other studies are as follows: ${ }^{10}$ for stones of $0.70 \mathrm{~cm}$ to 1.6 $\mathrm{cm}^{2}$ are $1386-2094$ upto 2500 equivalent to $14.5-17.8 \mathrm{Kv}{ }^{30}$ uses 4000 shocks $(10-18.1 \mathrm{Kv})$ with 90 shocks per minute with range of 5300-6295 shocks, ${ }^{31}$ used 400-6190 shocks per gram of stone. Over emission of ESWL shocks (more than 10,000 shocks) can affect renal scarring independent of stone size, so must be taken care for prevention of renal scaring $^{22}$. The number of shockwaves for complete communition of per gram of stones can be different with type of chemicals responsible to constitute the particular stone under treatment ${ }^{31}$.

The auxiliary treatment was required in 27 (10.8\%) patients before ESWL and 9.6\% of post ESWL patients during this study. While in literature the requirement of auxiliary treatment in different studies was as $2.85 \%$ to $43 \%{ }^{10-13}$

The number of sessions required for complete stone clearance can vary. The single session clearance of less than $1.5 \mathrm{~cm}$ stone is $70 \%{ }^{32}$.Different studies calculate on average 1.5 to 3 sessions per patient. ${ }^{6,24,30-32}$ The variation of stone structure could underlie the variation in stone fragility within type. ${ }^{31}$ The interval between two sessions was kept 710 days apart in this study so as time to pass gravel and stone fragments may be adequate. While in some other studies this interval was kept at 03-20 weeks. ${ }^{10}$ The frequency of residual stones can be reduced by appropriate indications of ESWL.Once a renal stone has formed, re treatment with ESWL can not ensure complete elimination of stones. ${ }^{19}$ ESWL is initial treatment of choice in patients with lower pole stones $\left(<2 \mathrm{~cm}^{2}\right.$ size) and stone free rates are acceptable ${ }^{15}$.

The stone clearance in our study is $89 \%$. The stone clearance rates in different studies is as low as 30\%to $60 \%$ for staghorn stones ${ }^{16,20}$ and for stones less than $3 \mathrm{~cm}$ it ranges from $60 \%$ to $98 \% .^{5,6,9-12,18-20,23-28,30-34}$ While stone clearance for upper ureteric stones ranges from $87 \%$ to $100 \%{ }^{2,23,33}$ This rate of stone clearance increases with the use of diuresis and prophylactic insertion of DJ stent along with reduction in the rate of complications especially for lower pole stones. ${ }^{14,32,33}$ A stone free state was defined as no radiological evidence of stone fragments $3 \mathrm{~mm}$ or less upto at least three months ${ }^{23}$. While in another study, it is declared that ESWL is considered failure if the stone fragments remained as residual after one month or retreatment or auxiliary procedure is required.

The average follow-up period in our study was 08 months (range 04 months to 15 months).In literature the follow-up period varies according to design of study. Different studies reported in national and international literature had follow-up period varying between 06 weeks to 05 years. ${ }^{15,19,26,32}$ Majority of the studies has recommended a period of 03-04 months. ${ }^{18,23,25,27,35}$ After ESWL periodical follow-up and checkup with ultrasonography will provide useful information. ${ }^{22}$ Nevertheless follow-up of stone patients after ESWL is mandatory and ultimate goal for treating stones by whatever means is to get patient free of stone and prevent recurrence. ${ }^{34,36}$ 


\section{Conclusion}

The optimal results of non invasive procedures like ESWL are advantageous for the patients. ESWL is an outdoor based procedure and without anaesthesia.It has lower morbidity and has limited the annual indications for surgery of stone disease. Open surgery is now drastically reducing and endoscopic and extracorporeal methods are increasing. There has been gradual increase in utilization of ESWL due to patient desire to get himself stone free. The stone free rates are significantly influenced by stone size.ESWL is recommendable primary treatment option for renal and ureteric stone patients for being safe, simple and effective. The frequency of residual fragments can be reduced by appropriate indication of ESWL.Best results can be achieved by trained operator, higher number of shocks and longer fluoroscopy time with out deterioration of renal function or scarring. The gadgetry for endoscopic manipulation must be available within the same setup if and when required for stenting or uretero-renoscopy.

\section{References}

1. Tombolini P, Rouppolo M, Bellorofonte C, Zaatar C,Follini M.Lithotripsy in the treatment of urinary lithiasis. J Nephrol. 2000 Nov-Dec; 13 Suppl 3: S71-82.

2. Grampas SA, Moore M, Chandhoke PS. 10 years experience with extracorporeal shockwave lithotripsy in the state of Colorado. J Endourol. 2000 Nov; 14 (9): 711-4.

3. Madbouly K, Sheir KZ, Elosbky E, Eracky I, Kenawy M. Risk factors for the formation of Steinstrasse after shock wave lithotripsy. A statistical model. J Urol, 2002 Mar; 167 (3): 1239-42.

4. Gonzalez Enguita C, Calahorra-Fernandez FJ, Cabrera Perez J, Garcia Cardoso J, Rodriguez-Minon Cifuentes JL, Garcia de la Pena E, Vela-Navarrete R. Surgery of Reno ureteral lithiasis. Current indications. Actas Urol Esp, 2001 Oct; 25 (9): 610-17.

5. Bendhack ML, Grimn MO, Ackermann R, Vogeli T. Primary treatment of ureteral stones by new multiline lithotripter. J Endourol.1999 Jun; 13 (5): 339-42.

6. Demirkesen O, Tansu N, Yaycioglu O, Onal B, Yalcin V, Solak V:Extracorporeal shockwave lithotripsy in pediatric population. J Endourol.1999 Apr; 13 (3): 14750.

7. Lograskis NF, Jewett MA, Luymes J, Honey RJ. Variation in clinical outcome following shock wave lithotripsy. J Urol, 2000 Mar; 163 (3): 721-5.

8. Perry KT, Smith ND, Weiser AC, User HM, Kundu SD, Nadler RB. The efficacy and safety of synchronous bilateral extracorporeal shockwave lithotripsy. J Urol, 2000 Sep. 164 (3pt1): 644-7.

9. Rizvi SA, Naqvi SA, Hussain Z, Hashmi A, Hussain M, Zafar MN, Sultan S, Mehdi H: Management of pediatric Urolithiasis in Pakistan. Experience with 1440 children. J Urol, 2003 Feb; 169 (2): 634-7.

10. Pienky AJ, Streem SB: Simultaneous versus staged bilateral extracorporeal shock wave lithotripsy: Long term effects on renal function. J Urol, 1999 Nov; 162 (5): 1591-3.

11. Jayanthi VR, Arnold PM, Koff SA. Strategies for managing upper tract calculi in young children. J Urol 1999 Sep; 162 (3pt2): 1234-7.

12. Kawano M, Yasumoto R, Tanaka T, Nishisaka N, Naganuma T, Kishimoto T: Extracorporeal shockwave lithotripsy for upper urinary tract stones using Dornier lithotripter compact: an experience in Japan.Hinyokikakiyo. 2000 Oct; 46 (10): 701-4.

13. Coz F, Orvieto M, Bustos M, Lyng R, Stein C, Hinrichs A, San Francisco I:Extracorporeal shockwave lithotripsy of 2000 urinary calculi with Modulith SL20. Success and failure according to size and location of stones. J Endourol, 2000 Apr; 14 (3): 239-46.

14. Al-Awadi KA, Abdul Halim H, Kehnide EO, AlTawheed A:Steinstrasse:A comparison of incidence with and without $\mathrm{J}$ stenting and effects of $\mathrm{J}$ stenting on subsequent management. BJU. Int. 1999 Oct; 84 (6): 618-21.

15. Deliveliotis C, Skolarikos A, Louras G, Kortakopoulos A, Karagiotis E:Extracorporeal shockwave lithotripsy for lower pole calculi: our experience. Int. J. Urol, 1999 Jul; 6 (7): 337-40.

16. Candau C, Saussine C, Lang H, Roy C, Faure F, Jacqmin D. Natural history of residual renal stone fragments after ESWL. Eur Urol 2000 Jan; 37 (1): 18-22.

17. Sampaio FJ. Renal collecting system anatomy, it's possible role in the effectiveness of renal stone treatment. Curr -opin Urol. 2001 Jul; 11 (4): 359-66.

18. Madboully K, Sheir KZ, Elsobky E: Impact of lower pole renal anatomy on stone clearance after shockwave lithotripsy: Fact or Fiction. J Urol. 2001 May; 165 (5): 1415-8.

19. Rousaud-Baron A, Millan F, Izquierdo-de-la Torre F, Rousaud F, Lopez L, Laurado H, Marti-Mal et J, de-laTorre Holguera P: Analysis and clinical course of residual lithiasis after shock wave renal treatment. Arch Esp Urol 2001 Nov; 54 (9): 1009-16.

20. Sorensen CM, Chandhoke PS. Is lower pole caliceal anatomy predictive of extracorporeal shock wave lithotripsy success for primary lower pole kidney stones?J Urol. 2002 Dec; 168 (6): 2377-82.

21. Gonzalez Enguita C, Rodriguez -Minon Cifuentes-JL, Garcia de la pena E, Jimenez-Jimenez JI, Vela Nava rrete R: Radiotransparent lithiasis.Diagnosis and treatment. Arch Esp Urol. 2001 Nov; 54 (9): 997-1008.

22. Ishito N, Takamoto H, Kunitomi K, Satoh E, Ishii A, Shiotuka Y, Sako S, Ohta N, Araki T. Clinical study of influential factors on renal scaring after ESWL monotherapy for renal stone disease. Nippon Hinyokika Gakki Zashi, 2002 Nov; 93 (7): 750-7.

23. Ather MM, Noor MA. Does size and site matter for renal stones upto $30 \mathrm{~mm}$ in size in children treated by extracorporeal lithotripsy. Urology, 2003 Jan; 61 (1): 212-5. 
24. Orsola A, Diaz I, Caffarati J, Izquierdo F, Alberola J, Garat JM: Staghorn calculi in children: treatment with monotherapy extracorporeal shock wave lithotripsy. J Urol 1999 Sep: 162 (3pt2): 1229-33.

25. Nabi G, Baldo O, Cartledge J, Cross W, Joyce AD, Lloyd SN: The impact of the Dornier compact Delta Lithotripter on management of primary ureteric calculi. Eur Urol, 2003 Oct; 44 (4): 482-6.

26. Amanullah, Rasheed AS, Ali QS, Hussain MJ: Extracorporeal shockwave lithotripsy. Efficacy of in situ Echo guidance in upper and lower ureteric calculi. The Professional, 2008 (July-Sep); 15 (03): 367-70.

27. Elosbky E, Sheir KZ, Madbouly K, Mokhtar AA. Extracorporeal shockwave lithotripsy in children. Experience using two second generation lithotripters. BJU. Int 2000 Nov; 86 (7): 851-6.

28. Robert M, Lanfery P, Rey G, Guiter J, Navratil H: Analgesia in ESWL: comparative study of kidney and upper ureteric stones treatments. J Endourol. 1999 JulyAug: 13 (6): 391-5.

29. Muzzamil MT, Usman MK, Ghauri S: Extracorporeal shockwave lithotripsy; Impact of diuresis on clearance of lower pole renal calculi. The Professional, 2008 (Apr-Jun); 15 (2): 193-99.
30. Azm TA, Hijazy H: Effects of diuresis on extractorporeal shockwave lithotripsy treatment of ureteric calculi. Scand-J-Urol-Nephrol. 2002; 36 (3): 209-12.

31. Tombolini P, Rouppolo M, Bellorofonte C, Zaatar C, Follini M: Lithotripsy in the treatment of urinary lithiasis. J Nephrol, 2000 Nov-Dec; 13 Suppl 3: S71-82.

32. Choong S, Whitfield H, Duffy P, Kellett M, Cuckow P, Van'thoff W. The management of Paediatric Urolithiasis. BJU. Int, 2000 Nov; 86 (7): 857-60.

33. Bierkens AF, Hendrikx AJ, Dela Rosette JJ, Stultiens GN, Beerlage HP, Arends AJ, Debruyne FM: Treatment of mid and lower ureteric calculi. Extracorporeal lithotripsy vs. Laser Ureteroscopy. A comparison of cost morbidity and effectiveness. Br J Urol, 1998 Jan; 81 (1): 31-5.

34. William JC Jr, Saw KC, Paterson RF, Hatt EK, NcAteer JA, Lingeman JE: Variability of renal stones fragility in shock wave lithotripsy. Urology, 2003 Jun; 61 (6): 1092-7.

35. Macnamara A, Hoskins P. Patient radiation dose during lithotripsy. Br J Radiol, 1999 May; 72 (857): 495-8.

36. Gerber GS: Combination therapy in the treatment of patients with staghorn calculi.Tech Urol. 1999 Sep; 5 (3): 155-8. 